\title{
Rapid Reversal of Liver Steatosis With Life Style Modification in Highly Motivated Liver Donors
}

\author{
Narendra S. Choudhary ${ }^{\star}$, Neeraj Saraf ${ }^{\star}$, Sanjiv Saigal ${ }^{\star}$, Dheeraj Gautam ${ }^{\dagger}$, Lipika Lipi ${ }^{\dagger}$, Amit Rastogi ${ }^{\star}$, Sanjay Goja*, \\ Palat B. Menon*, Prashant Bhangui", Sumana K. Ramchandra*, Arvinder S. Soin* \\ ${ }^{*}$ Medanta Liver Institute and ${ }^{\dagger}$ Department of Histopathology, Medanta, The Medicity, Gurgaon, India
}

\begin{abstract}
Background: Liver steatosis is the leading cause of donor rejection in living donor liver transplantation. Rapid weight loss is difficult to achieve in a short period of time, moreover it has been thought to worsen liver histology. Methods: Donors who had significant steatosis based on liver biopsy were recommended $1200 \mathrm{Kcal} / \mathrm{day}$ and a minimum of $60 \mathrm{~min} /$ day moderate cardio training. Two patients were advised statins for dyslipidemia. None of the donors had metabolic syndrome. A second ultrasound guided liver biopsy was done at $28 \pm 10$ days. Donors with nonalcoholic steatohepatitis/fibrosis or $>\mathbf{3 0} \%$ steatosis were not included. Results: From July 2010 to January 2015, 16 donors were advised aggressive life style modification after initial biopsy; 15 (10 males, age $27.5 \pm 6.5$ years, baseline body mass index $28.4 \pm 2.1 \mathrm{Kg} / \mathrm{M}^{2}$ ) successfully reduced weight and 14 underwent donation after favorable second biopsy. Mean weight loss was $7 \pm 4.3 \mathrm{~kg}(8.4 \pm 4.6 \%)$. Second liver biopsy was done at $28 \pm 10$ days, there was decrease in steatosis in all but one including normalization of liver biopsy in 7 donors. Three donors had mild inflammation on first biopsy and they had improvement in second biopsy. All the donors and their recipients had an uneventful post-operative course. Conclusion: Steatosis can be reversed in a short duration by aggressive life style modifications in highly motivated liver donors. ( $\mathrm{J}$ CLIN EXP HEPATOL 2015;5:123-126)
\end{abstract}

$\mathrm{N}$ on-alcoholic fatty liver disease (NAFLD) is common amongst obese population and weight loss has been shown to reverse all histological aspects of NAFLD including steatosis, inflammation, ballooning and fibrosis. ${ }^{1,2}$ In addition NAFLD is leading cause of donor rejection in living donor liver transplantation program at our centre. ${ }^{3}$ Achievement and maintenance of weight loss is difficult in clinical practice. Data on effect of weight loss on liver histology in NAFLD patients has come from either clinical trials which achieve weight loss on a long term or from studies of bariatric surgery patients. Rapid weight loss is not recommended due to fear of worsening of inflammation, ${ }^{4}$ moreover is difficult to achieve in clinical practice in poorly motivated asymptomatic NAFLD patients. However, rapid weight loss is often only option for prospective liver donors (in absence of other donors in family) who want to donate their liver to their loved ones as they can't wait too long as they are too sick or have hepatocellular carcinoma. We report our

Keywords: liver biopsy, donor, life style modification, exercise, diet Received: 10.3.2015; Accepted: 9.4.2015; Available online: 21.4.2015

Address for correspondence: Neeraj Saraf, Medanta Liver Institute, Medanta, The Medicity, Gurgaon, India. Tel.: +91 9899077795

E-mail: neerajsaraf@hotmail.com

Abbreviations: ALT: alanine transaminase; ALT: aspartate transaminase; BMI: body mass index; LAI: liver attenuation index; LDLT: living donor liver transplantation; NAFLD: non-alcoholic fatty liver disease

http://dx.doi.org/10.1016/j.jceh.2015.04.002 experience of this unique cohort (young donors, no comorbidities, emotionally motivated for weight loss on a short term basis) of 15 prospective liver donors who had paired liver biopsies.

\section{MATERIAL AND METHODS}

The study was conducted at a tertiary care centre in a high volume LDLT centre. The study was approved by institute's ethical committee. As part of donor work-up, a non-contrast CT scan was used as a non-invasive modality to assess donor steatosis. We use liver attenuation index (LAI, defined as attenuation index of liver minus attenuation index of spleen measured at multiple areas). A difference of less than $5^{5}$ or liver attenuation value $<53$ (based on our previous experience) was taken as suggestive of hepatic steatosis.

Prospective liver donors with liver attenuation index value between 0 and 5 or liver attenuation $<53 \mathrm{HU}$, presence of dyslipidemia or body mass index $>28 \mathrm{~kg} / \mathrm{m}^{2}$ were taken for liver biopsy before liver donation. Donors with non-alcoholic steatohepatitis were excluded from the study as we do not take them as donors. Donors who had a remnant volume less than 30\% (the lower limit of acceptance) were advised for liver biopsy to rule out steatosis and inflammation and were taken up for a repeat liver biopsy before donation. From July 2010 to January 2015, 16 prospective liver donors were advised for weight loss based on significant steatosis on liver biopsy. They were 
advised $1200 \mathrm{Kcal}$ per day diet (including $50-60 \mathrm{~g}$ proteins) and minimum of 60 min moderate activity in the form of brisk walk (200-400 Kcal) as exercise, they were free to do more exercise if they wanted to do. Fourteen prospective donors were taken up for repeat liver biopsy. Two of these donors had $10 \%$ steatosis, still they were advised for life style modification and second biopsy to increase donor safety as they had borderline remnant. Second liver biopsy was done if they had some weight loss and favorable repeat LAI assessment.

\section{Statistical Methods}

The results are shown as mean (SD), \% and numbers. The baseline and after weight loss parameters were compared with paired t-test (SPSS 16, Chicago Inc).

\section{RESULTS}

In the given period, liver biopsies were done in 374 actual donors (after exclusion of NASH/fibrosis), 188 of these were diagnosed as non-alcoholic fatty liver. The study cohort consisted of 16 prospective liver donors who underwent paired liver biopsies before liver donation and 14 (7.4\% of all NAFLD donors) of them had successful donation as shown in flow chart (Figure 1). In the same time, 2 donors had non-alcoholic steatohepatitis and 2 had fibrosis and were not taken as donors. They were advised for weight loss by life style modification as they had $>20 \%$ steatosis or borderline remnant. Fifteen donors (10 males and 5 females) were taken up for a second liver biopsy after some weight loss (no cut-off predetermined) and favorable LAI assessment, one donor who could not loss weight was not taken up for repeat liver biopsy. Mean age of the donors was $27.5 \pm 6.5$ years and baseline
Table 1 Characteristics of 15 Donors.

\begin{tabular}{|lllccccc}
\hline S. no & $\begin{array}{c}\text { Age } \\
\text { years }\end{array}$ & $\begin{array}{c}\text { Sex Baseline } \\
\text { BMI } \\
\text { Kg/m }\end{array}$ & $\begin{array}{c}\text { \%eight } \\
\text { change }\end{array}$ & $\begin{array}{c}\text { Biopsy } \\
\text { interval }\end{array}$ & $\begin{array}{c}\text { Steatosis } \\
\text { first } \\
\text { biopsy }\end{array}$ & $\begin{array}{c}\text { Steatosis } \\
\text { second } \\
\text { biopsy }\end{array}$ \\
\hline 1 & 36 & M & 25.9 & 7.6 & 38 & 25 & 10 \\
\hline 2 & 36 & F & 28.9 & 4 & 34 & 25 & $<5$ \\
\hline 3 & 27 & M & 25.2 & 13.8 & 50 & 15 & 10 \\
\hline 4 & 22 & M & 27.3 & 6.3 & 22 & 10 & $<5$ \\
\hline 5 & 38 & F & 29.5 & 11.5 & 21 & 10 & $<5$ \\
\hline 6 & 28 & M & 28 & 3.6 & 13 & 15 & $<5$ \\
\hline 7 & 23 & M & 25.9 & 14.6 & 29 & 20 & 10 \\
\hline 8 & 21 & F & 27.5 & 5.5 & 32 & 15 & $<5$ \\
\hline 9 & 20 & M & 26.7 & 2.5 & 21 & 15 & 5 \\
\hline 10 & 36 & F & 31.6 & 7.6 & 21 & 15 & $<5$ \\
\hline 11 & 21 & F & 22.7 & 3.5 & 21 & 15 & 10 \\
\hline 12 & 21 & M & 28.1 & 14.7 & 28 & 25 & 25 \\
\hline 13 & 23 & M & 26.6 & 8 & 21 & 20 & 5 \\
\hline 14 & 29 & M & 31.3 & 15.6 & 44 & 20 & $<5$ \\
\hline 15 & 32 & M & 28.4 & 6.9 & 21 & 20 & 10 \\
\hline & & & & & & & \\
\hline
\end{tabular}

BMI was $28.4 \pm 2.1 \mathrm{Kg} / \mathrm{M}^{2}$. Characteristics of these 15 donors are shown in Table 1. All of these donors had normal liver enzymes as shown in Table 2. None of these prospective liver donors had diabetes, hypertension or metabolic syndrome. Mean weight loss was $7 \pm 4.3 \mathrm{~kg}(8.4 \pm 4.6 \%$ of initial body weight). Lipid profile of 15 donors was as follows: total cholesterol $155 \pm 45 \mathrm{mg} / \mathrm{dL}$, triglycerides $122 \pm 65 \mathrm{mg} / \mathrm{dL}$, low density lipoprotein $95 \pm 38 \mathrm{mg} / \mathrm{dL}$ and high density lipoprotein $38 \pm 9.8 \mathrm{mg} / \mathrm{dL}$. Three of these donors had mild inflammation at baseline liver

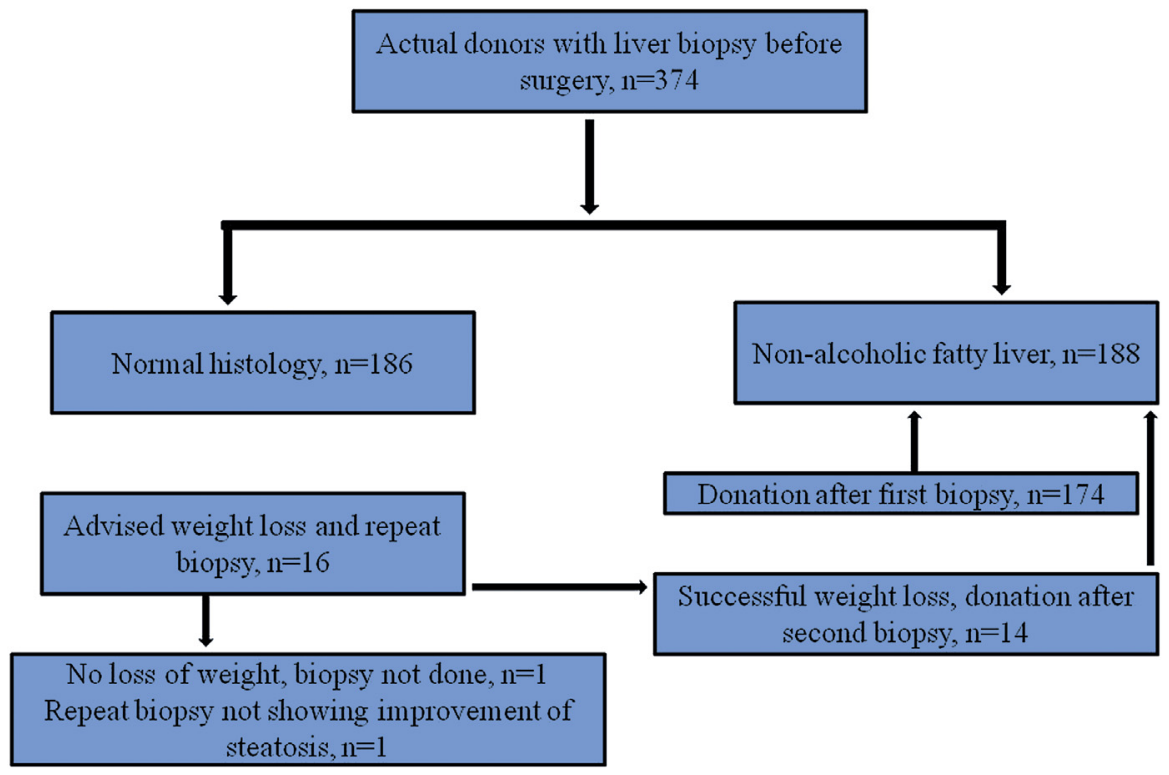

Figure 1 Selection of donors for paired biopsy. 
Table 2 Pre and Post Life Style Intervention Data of 15 Donors.

\begin{tabular}{lccc}
\hline Parameter & Pre weight loss & After weight loss & $\boldsymbol{P}$ value \\
\hline Weight $(\mathrm{kg})$ & $79.4 \pm 11.3$ & $72.6 \pm 9.2$ & 0.000 \\
$\mathrm{BMI} \mathrm{Kg} / \mathrm{m}^{2}$ & $28.4 \pm 2.1$ & $25.7 \pm 2.1$ & 0.006 \\
$\mathrm{AST} \mathrm{IU} / \mathrm{ml}(\mathrm{n}=7)$ & $33.1 \pm 7.6$ & $27.5 \pm 5.9$ & 0.856 \\
$\mathrm{ALT} \mathrm{IU} / \mathrm{ml}(\mathrm{n}=7)$ & $52.1 \pm 24.9$ & $36.4 \pm 8.4$ & 0.097 \\
LAl $(n=13)$ & $5.6 \pm 4.6$ & $7.9 \pm 4.7$ & 0.008 \\
\hline
\end{tabular}

AST: aspartate transaminase, ALT: alanine transaminase, LAl: liver attenuation index (defined as attenuation index of liver minus attenuation index of spleen).

biopsy which improved on second biopsy. Second liver biopsy after weight loss showed reversal or improvement of steatosis in all but one of the donors. None of the donors had worsening of inflammation on the follow up second liver biopsy at $28 \pm 10$ days. As shown in Table 2, there was significant improvement in weight and liver attenuation index. There was trend of improvement in aspartate transaminase (AST) and alanine transaminase (ALT) values; however, it could not reach statistical significance. We did not get lipids second time, so we do not have comparison of lipids at time of second biopsy. Fourteen donors underwent liver donation successfully and there was no morbidity noted in any of them, one prospective donor (number 12 in Table 1) had similar steatosis on second biopsy despite weight loss and he could not donate as prospective recipient died few days later.

\section{DISCUSSION}

Our study highlights importance of emotional motivation for weight loss and it shows that in young subjects without co-morbidities, short term weight loss reverses steatosis and it does not worsen inflammation. Earlier studies suggest that weight loss $>1.6 \mathrm{~kg}$ per week may worsen hepatic inflammation and portal fibrosis. It may be related to the increased free fatty acids release and proinflammatory cytokines release by visceral fat. ${ }^{4}$ Most of the data on effect of rapid weight loss on liver histology has come from bariatric surgery studies ${ }^{2,6-12}$ where population is morbidly obese, older, had co-morbidities or metabolic syndrome and often first liver biopsy showed significant steatosis/ even fibrosis. Only few of these studies have shown worsening of second liver biopsy, however there are two limitations in interpreting data from bariatric surgery studies; majority of these studies have not shown any worsening of second liver biopsy and have shown marked improvement in all histological aspects and there are some chances of sampling error in first liver biopsy which have missed milder degrees of fibrosis or some inflammation.

There is not much data on rapid weight loss in normal population with NAFLD for two reasons; first it is very difficult to achieve and second, there is no need for rapid weight loss for improvement of steatosis/inflammation. Our study is not comparable to older studies for these reasons and it provides a unique opportunity to study effect of rapid weight loss on young healthy population with milder form of NAFLD. American association for study of liver disease (AASLD) guidelines recommend 10\% weight loss for improvement of steatosis and inflammation. ${ }^{1}$ Four donors in present study lost $<5 \%$ weight before second liver biopsy, however, they also achieved reversal of steatosis showing that even milder form of weight loss with life aggressive exercise can reverse steatosis. Other studies evaluating role of rapid weight reduction in donor populations also have shown favorable results. ${ }^{13,14}$ Our study subjects had higher BMI and second liver biopsy was done earlier as compared to these studies. One of the donors (number 12) had similar steatosis despite 14.7\% weight loss (more than several other donors). We reviewed his CT before first and second biopsy. The second CT showed focal areas of fat as compared to first CT which showed diffuse fatty infiltration (similar liver attenuation values). Since the second CT showed focal fat with normal intervening areas, biopsy may not be representative of reduction in steatosis.

The present study has limitation regarding number of subjects, however, as earlier said, this is a unique cohort where biopsy is not recommended otherwise (normal liver enzymes, no risk factors for advanced NAFLD) and it is not possible to asses effect of rapid weight loss in this subgroup of NAFLD. Our study has great implications for developing countries or Asian countries where main form of liver transplantation is living donor transplantation as donor safety, good outcome of recipients and timing of transplant are important aspects of living donor liver transplantation. Our data also shows importance of motivation regarding weight loss and safety of rapid weight loss as we know that weight loss is difficult to achieve in clinical practice. In conclusion, we show impressive results of weight loss (that could be achieved over short term) in decreasing liver steatosis; moreover, it doesn't lead to inflammation in healthy subjects.

\section{CONFLICTS OF INTEREST}

All authors have none to declare.

\section{ACKNOWLEDGEMENTS}

Mr Yogesh Saini (data collection).

\section{REFERENCES}

1. Chalasani N, Younossi Z, Lavine JE, et al. The diagnosis and management of non-alcoholic fatty liver disease: practice Guideline by the American Association for the Study of Liver Diseases, American College of Gastroenterology, and the American Gastroenterological Association. Hepatology. 2012;55:2005-2023. 
2. Furuya Jr CK, de Oliveira CP, de Mello ES, et al. Effects of bariatric surgery on nonalcoholic fatty liver disease: preliminary findings after 2 years. J Gastroenterol Hepatol. 2007;22:510-514.

3. Kotecha HL, Saraf N, Saigal S et al. NAFLD is the leading cause of donor rejection in living donor liver transplantation. J Clin Exp Hepatol 3:S3. http://dx.doi.org/10.1016/j.jceh.2013.03.

4. Rafiq N, Younossi ZM. Effects of weight loss on nonalcoholic fatty liver disease. Semin Liver Dis. 2008;28:427-433.

5. Limanond P, Raman SS, Lassman C, et al. Macrovesicular hepatic steatosis in living related liver donors: correlation between CT and histologic findings. Radiology. 2004;230:276-280.

6. Dixon JB, Bhathal PS, Hughes NR, O'Brien PE. Nonalcoholic fatty liver disease: improvement in liver histological analysis with weight loss. Hepatology. 2004;39:1647-1654.

7. Luyckx FH, Desaive C, Thiry A, et al. Liver abnormalities in severely obese subjects: effect of drastic weight loss after gastroplasty. Int J Obes Relat Metab Disord. 1998;22:222-226.

8. Silverman EM, Sapala JA, Appelman HD. Regression of hepatic steatosis in morbidly obese persons after gastric bypass. Am J Clin Pathol. 1995;104:23-31.
9. Tai CM, Huang CK, Hwang JC, et al. Improvement of nonalcoholic fatty liver disease after bariatric surgery in morbidly obese Chinese patients. Obes Surg. 2012;22:1016-1021.

10. Mattar SG, Velcu LM, Rabinovitz M, et al. Surgically-induced weight loss significantly improves nonalcoholic fatty liver disease and the metabolic syndrome. 2005;242:610-617. discussion 618-620.

11. Liu X, Lazenby AJ, Clements RH, Jhala N, Abrams GA. Resolution of nonalcoholic steatohepatits after gastric bypass surgery. Obes Surg. 2007;17:486-492.

12. Clark JM, Alkhuraishi AR, Solga SF, Alli P, Diehl AM, Magnuson TH. Roux-en-Y gastric bypass improves liver histology in patients with non-alcoholic fatty liver disease. Obes Res. 2005;13:1180-1186.

13. Jin YJ, Kim KM, Hwang S, et al. Exercise and diet modification in non-obese non-alcoholic fatty liver disease: analysis of biopsies of living liver donors. J Gastroenterol Hepatol. 2012;27:13411347.

14. Oshita A, Tashiro H, Amano H, et al. Safety and feasibility of diet-treated donors with steatotic livers at the initial consultation for living-donor liver transplantation. Transplantation. 2012;93: 1024-1030. 